\title{
FORMAÇÃO DOCENTE E PNE (2014-2024): UMA ABORDAGEM INICIAL
}

\author{
J. K. C MORAIS , A. L. S. HENRIQUE \\ Instituto Federal de Educação, Ciência e Tecnologia do Rio Grande do Norte (IFRN) \\ kaio-ca-valcante@hotmail.com*
}

Submetido 04/03/2017 - Aceito 20/12/2017

DOI: $10.15628 /$ holos.2017.4512

\section{RESUMO}

O presente artigo insere-se nas discussões a respeito das políticas públicas voltadas para formação de professores da educação básica no Brasil. Nosso objetivo é analisar as metas e estratégias do Plano Nacional de Educação (2014-2024) voltadas para formação de professores da educação básica. Nossa investigação é do tipo bibliográfica e documental e utiliza-se do método histórico-dialético. Consultamos autores como: Engels (1995) e Santos (1981). Os resultados evidenciam que das vinte metas do plano, quatro estão centradas na formação e valorização do professor da educação básica. Duas delas discorrem a respeito especificamente da formação inicial e continuada. Percebemos que as estratégias abrem espaço para investimento de caráter público na esfera privada, sobretudo no âmbito da formação inicial em licenciaturas. Esse caráter evidencia a preocupação do Estado em servir aos interesses dos donos do capital, firmando assim a sua principal função ideológica.

PALAVRAS-CHAVE: Estado, Políticas Públicas, Formação de Professores, PNE.

\section{TEACHING AND TRAINING NEP: (2014-2024) AN INITIAL APPROACH}

\section{ABSTRACT}

$O$ The present article is part of on going discussions in the respect of public policies for Basic Education Teacher Training in Brazil. Our Goal is to analyze how goals and strategies of the National Education Plan (2014-2024) aimed at Basic Education Teacher Training. Our Research is to do a kind of Bibliographical and documentary and to use the historical and dialectical method. We consulted Authors: Engels (1995) and Santos (1981). The results show of Twenty planned
Goals, four are centered on Training and Enhancement of Basic Education teachers. Two of them are in specific respect of initial and continuation training. We realize that Open Space Public Strategies character Investment in private sphere space, there is especially scope for the initial training IN degrees. This character demonstrates the State's concern to serve the interests of capital investers, thus entering into its main ideological function.

KEYWORDS: State, Public policy, teacher training, NEP. 


\section{CONTEXTUALIZANDO O ESTUDO}

A presente pesquisa decorre das discussões na disciplina Estado e Políticas Educacionais do mestrado acadêmico do Programa de Pós-Graduação em Educação Profissional do Instituto Federal de Educação, Ciência e Tecnologia do Rio Grande do Norte (IFRN). No momento, problematizamos as interfaces do Estado e das políticas educacionais brasileiras para a educação. Em decorrência desses momentos em sala de aula, foi encaminhado à produção de um artigo científico para a disciplina que versasse sobre o Plano Nacional da Educação (2014-2024) e sua relação com as políticas de formação de professores no Brasil.

É preciso esclarecer que para compreender o Plano Nacional de Educação (PNE), precisamos centrar nossos olhares nas metas e, sobretudo, nas estratégias, uma vez que as últimas evidenciam os caminhos para alcançar as primeiras. Sendo assim, destacamos como objetivo do presente trabalho analisar as metas e estratégias do PNE (2014-2024) voltadas para a formação de professores que atuam na Educação Básica, bem como para educação profissional (EP).

De uma forma geral, o PNE, Lei no 13.005/2014, é um instrumento de planejamento que orienta a execução e o aprimoramento de políticas públicas voltadas para a educação.

O documento foi construído a partir do planejamento e discussões de vários segmentos da sociedade civil, dentre eles: movimentos sociais; gestores, setor privado da educação brasileira; instituições de ensino superior públicas, dentre outros. Percebemos, portanto, que o resultado do PNE é fruto dos atores sociais que constituem a educação como um todo, desde a esfera pública à privada (BRASIL, 2014).

A partir do objetivo proposto para esse artigo, bem como de uma breve contextualização da construção do PNE e da leitura da Lei que o aprova, surgiram algumas questões impulsionadoras: o que nos evidencia o PNE com relação à formação de professores, bem como sua valorização e carreira profissional? Especificamente, como o PNE aborda a formação de professores para atuar na EP? A política de formação de professores atende a quais interesses?

Para responder a essas questões, utilizaremos o método histórico-dialético, por compreender que ele nos oferece os pressupostos para o entendimento das contradições da realidade, algo que se coaduna com o objetivo proposto nesta produção (FRIGOTTO, 2000).

Logo, para compreensão das contradições do objeto de estudo em questão, foi preciso recorrer aos estudos de autores como Engels (1995) e Santos (1981) para que pudéssemos problematizar o conceito de Estado capitalista e suas implicações nas políticas públicas educacionais, como por exemplo, o próprio PNE.

O estudo encontra-se organizado em quatro partes: esta introdução e mais três tópicos. O primeiro deles faz menção ao conceito de Estado capitalista, políticas públicas e marcos legais para compreender o PNE como um documento contextualizado, situado historicamente e, que, portanto, carrega as contradições do espaço-tempo em que foi construído. Já o segundo, de caráter mais descrito e discursivo, aborda especificamente o PNE (2014-2024), a partir das questões elencadas anteriormente. No terceiro traçamos as considerações finais. 


\section{O ESTADO CAPITALISTA E AS POLÍTICAS PÚBlicAS VOLTADAS PARA A FORMAÇÃO DOCENTE: UMA BREVE ABORDAGEM}

Antes de adentrar nas questões inerentes ao PNE, é necessário situar o leitor com relação a alguns pontos relevantes para a compreensão do objeto de estudo em questão. Precisamos problematizar o conceito de Estado na sociedade atual e entender as suas implicações para o desenvolvimento das políticas públicas educacionais e, mais precisamente, das políticas de formação de professores.

Sabemos que hoje vivemos em uma sociedade capitalista. Esta é caracterizada pela hegemonia da burguesia para com os meios de produção. Para alcançar tal finalidade, os donos do capital utilizam da força de trabalho dos trabalhadores para gerar mais lucros, a partir de técnicas específicas de produção.

Nesse sentido, percebemos que a sociedade é dividida entre aqueles que são proprietários do meio de produção e aqueles que vendem sua força de trabalho. Os primeiros são chamados, nesse artigo, de capitalistas, já os segundos de trabalhadores.

O Estado, enquanto entidade jurídica e política da sociedade civil, encontra-se também inserido na lógica do capital. De acordo com Santos (1981), o Estado aparece como um articulador dessas duas classes - capitalistas e trabalhadores -, sendo que uma dessas articulações é dominante. Em outras palavras, se os capitalistas são os proprietários dos meios de produção, logo, o Estado também está servindo aos seus interesses - acumular mais capital.

O Estado é, assim, a forma política dessas relações e caracteriza-se pela exterioridade do político ao econômico e pela superordenação do primeiro, enquanto expressão do interesse comum, ao segundo. Dessa forma, o Estado assegura de forma jurídica e política as condições gerais da reprodução das relações de exploração, garantindo a liberdade dos cidadãos no mercado para vender sua força de trabalho aos donos do capital, institucionalizando assim, a principal característica do modo de produção capitalista (SANTOS, 1981).

De acordo com Engels (1995), essa conjuntura do Estado, subordinado aos interesses do capital, é elemento fundamental para compreensão do conceito de Estado. O autor acredita que o Estado não existiu desde sempre. Segundo ele, existiram diversas sociedades que prescindiram dessa instituição.

O Estado torna-se necessário a partir de certo grau de desenvolvimento econômico, no momento em que a propriedade privada gera as desigualdades sociais e surgem as classes sociais. Com as classes, surgem a luta de classes e a necessidade do Estado para proteger a classe economicamente dominante. A classe que detém os meios de produção institucionaliza, através do Estado, seu controle econômico, por meio de instituições políticas e jurídicas (ENGELS, 1995). Dessa forma, o conceito de Estado, numa visão marxista, está relacionado com a institucionalização das relações sociais de dominação.

Mesmo que breve, esses pressupostos básicos do conceito de Estado, a partir de uma visão marxista, nos evidencia o papel do Estado, sobretudo no modo de produção capitalista. Sabemos que, por apresentar uma característica jurídica, o Estado propõe, regula e avalia as políticas públicas, bem como suas finalidades. 
No que se refere às políticas públicas, compreendemos que estas, em um plano concreto, dizem respeito aos recursos de poder que operam em sua definição e que têm nas instituições do Estado, sobretudo na máquina governamental, o seu principal referente (AZEVEDO, 2004).

Estas políticas públicas são definidas, implementadas, reformuladas ou desativadas com base na memória da sociedade ou do Estado em que têm lugar e que, por isso, guardam estreita relação com as representações sociais que cada sociedade desenvolve sobre si própria (AZEVEDO, 2004). Ou seja, as políticas públicas têm estreita relação com a sociedade civil.

Azevedo (2004), por sua vez, aponta a existência de três tipos de políticas públicas: as redistributivas, as distributivas e as regulatórias.

As políticas públicas redistributivas consistem em redistribuição de renda na forma de recursos e/ou de financiamento de equipamentos e serviços públicos.

As políticas públicas distributivas implicam nas ações cotidianas que todo e qualquer governo precisa fazer. Elas dizem respeito à oferta de equipamentos e serviços públicos, mas sempre feita de forma pontual ou setorial, de acordo com a demanda social ou a pressão dos grupos de interesse. O seu financiamento é feito pela sociedade como um todo através do orçamento geral de um estado (OLIVEIRA, 2015).

Por último, há as políticas públicas regulatórias, que incidem na elaboração das leis que autorizaram os governos a fazerem determinada política pública redistributiva ou distributiva. Se estas duas implicam no campo de ação do poder executivo, a política pública regulatória é, essencialmente, campo de ação do poder legislativo (OLIVEIRA, 2015).

No que diz respeito às políticas públicas educacionais, Oliveira (2015) compreende que estas versam sobre as decisões do governo, com base na dinâmica social, que tem incidência no ambiente escolar enquanto lugar de ensino-aprendizagem. Portanto, são políticas pensadas, planejadas e desenvolvidas para o espaço escolar. Em meio a isso, encontram-se as políticas de formação de professores.

Exposto esse cenário, centraremos nosso olhar nos marcos legais do Estado brasileiro, com a finalidade de localizar diretrizes na área de educação que incidam em políticas públicas para a formação de professores. Esse caminho se faz relevante, posto que o PNE faz menção a esses documentos de caráter mais global e hierarquicamente superiores.

A Constituição Federal de 1988, constituída por representantes do povo brasileiro reunidos em Assembleia Nacional constituinte, tem o objetivo de instituir um Estado democrático; uma sociedade fraterna, pluralista e sem preconceitos; garantindo direitos sociais e individuais à liberdade, segurança, bem-estar, desenvolvimento, igualdade e justiça.

Nesse contexto, os direitos sociais, conforme Art. $6^{\circ}$ da CF/1988, são: o acesso à educação, saúde, alimentação, trabalho, moradia, lazer, segurança, previdência social e a proteção à maternidade, à infância e aos desamparados.

Dentre os direitos sociais preconizados pela Constituição Federal, ressalta-se o direito inquestionável à educação, apresentado como direito "de todos" e de responsabilidade do Estado e da família com "coparticipação" da sociedade. Convém lembrar que cabe privativamente à União legislar sobre as diretrizes e bases da educação, conforme aponta artigo 22 da Lei Magna. 
Assim, na atual constituição brasileira este direito é tratado especificamente na Seção I do Capítulo III nos Artigos: 205 - Finalidades da Educação; Art. 206 - Princípios Básicos do Ensino; Art. 207 - Autonomia das universidades; Art. 208 - Educação Básica obrigatória; Art. 209 Condições para o Ensino Privado; Art. 210 - Organização Curricular do Ensino Fundamental; Art. 211 - regime de colaboração; Art. 212 e 213 versam sobre os Recursos Financeiros para a Educação (BRASIL, 1988).

O Art. 214, especificamente, volta-se para a questão do PNE. A lei estabelece o plano nacional de educação, de duração decenal, tendo o objetivo de articular o sistema nacional de educação em regime de colaboração e definir diretrizes e objetivos de implementação com o intuito de assegurar a manutenção e desenvolvimento do ensino nos mais diversos níveis, etapas e modalidades. Além disso, o mesmo artigo estipula os objetivos do PNE, dentre eles, destacamos a universalização e a melhoria da qualidade do ensino (BRASIL, 1988).

Os artigos supracitados discorrem sobre os princípios políticos, estabelecem estruturas e procedimentos, poderes e direitos, para que seja promovida uma educação igualitária. Para tanto, a educação é tratada como direito de todos e dever do Estado e da família, promovida com a colaboração da sociedade, apresentando como objetivos: o pleno desenvolvimento da pessoa; o preparo para o exercício da cidadania e a qualificação para o trabalho (BRASIL, 1988).

Para que aconteça a educação determinada pela Constituição Federal em vigor são necessários liberdade de aprender, ensinar, pesquisar e divulgar o pensamento, a arte e o saber. Para tanto, se fazem necessários processos didáticos bem articulados e professores bem preparados.

O trabalho docente, neste contexto, é parte integrante do processo educativo mais global, no qual os membros da sociedade têm o direito de serem preparados para o exercício da cidadania e qualificados para o trabalho. Assim, pensando no profissional da educação escolar que tem papel fundamental nesse processo de formação, a Constituição assegura a valorização desses profissionais da rede pública, assegurando o direito a plano de carreira, piso salarial nacional e condições de trabalho.

A Constituição Federal é uma lei mais geral, que contempla diversos aspectos da nossa sociedade, dentre eles o da educação. Entretanto, não desenvolve discussão a respeito da formação do professor. É na Lei no 9.394/96, Lei de Diretrizes e Bases da Educação (LDB), que localizamos algumas discussões voltadas especificamente para essa finalidade. Por exemplo, o título VI - "Profissionais da Educação" e artigos que versam sobre a formação de professores, como o art. 62 que delimita a formação inicial de professores em cursos de licenciaturas como formação mínima para exercer um cargo docente.

Outros artigos da Lei versam sobre formação inicial, formação continuada, valorização docente, plano de cargos e carreira, dentre outros. A LDB é a lei geral da educação brasileira, e, portanto, todas as demais leis relativas à educação devem se coadunar com seus princípios, inclusive o PNE, por isso, sua relevância na delimitação das políticas públicas brasileira.

Compreendemos que o Estado brasileiro é majoritariamente capitalista, uma vez que serve aos interesses da classe dominante. As políticas públicas brasileiras constitucionalizam essa relação materializando-a a partir de ações governamentais que transfere recursos da esfera 
pública para a esfera privada. Este fator se constitui enquanto um dos pontos discutidos no próximo tópico.

\section{PLANO NACIONAL dE EDUCAÇÃo (2014-2024) E A FORMAÇÃo dE PROFESSORES: DISCUSSÕES INICIAIS}

Como vimos no tópico anterior, as políticas públicas podem ser do tipo redistributivas, distributivas e regulatórias. O PNE atual se enquadra como regulatória. Sendo assim, o PNE, tomando como base a Constituição Federal e a LDB vigente, direciona as políticas públicas de caráter distributivas e redistributivas no que concerne à Educação brasileira.

Em meio a isso, a Lei no 13.005, sancionada pela presidente Dilma Rousseff no dia 25 de junho de 2014, determina metas e estratégias para a educação brasileira para os próximos dez anos (2014-2024).

O PNE surge com o intuito de reforçar o art.214 da Constituição Federal que estabelece uma articulação entre o sistema nacional de educação em regime de colaboração, por meio de ações integradoras dos poderes públicos das diferentes esferas federativas que conduzam a: erradicação do analfabetismo; universalização do atendimento escolar; melhoria da qualidade do ensino; formação para o trabalho e promoção humanística, científica e tecnológica do País.

A Emenda Constitucional no 59/2009 aperfeiçoou o objetivo do PNE: articular o sistema nacional de educação em regime de colaboração e definir diretrizes, objetivos, metas e estratégias de implementação para assegurar a manutenção e desenvolvimento do ensino, em seus diversos níveis, etapas e modalidades, por meio de ações integradas das diferentes esferas federativas.

A execução do PNE e o cumprimento de suas metas e estratégias são e serão objeto de monitoramento contínuo e de avaliações periódicas, realizados por quatro instâncias: o Ministério da Educação - MEC; Comissão de Educação da Câmara dos Deputados e Comissão de Educação, Cultura e Esporte do Senado Federal; Conselho Nacional de Educação - CNE e o Fórum Nacional de Educação. Apesar de as metas e estratégias serem executadas tendo como princípio o regime de colaboração entre as esferas do poder público, fica a cargo da União e, consequentemente, seus órgãos reguladores, desenvolver a avaliação do acompanhamento da materialização do PNE (BRASIL, 2014).

Dessa forma, percebemos a função do Estado, enquanto elemento de avaliação das políticas públicas, algo que se coaduna com o propósito do Estado mínimo na sociedade capitalista. Nessa prerrogativa, o Estado é mínimo para as questões que interessam à classe trabalhadora, mas máximo para os interesses dos capitalistas.

A partir dessas constatações, notamos que o PNE estabelece um regime de colaboração para materializar as metas e as estratégias, entretanto, no que tange ao desenvolvimento das avaliações do PNE, observa-se que os órgãos da União é que desenvolvem essa função, algo que coaduna com a própria finalidade do Estado, uma vez que este é instrumento regulatório e avaliativo das políticas públicas e, mais especificamente, daquelas voltadas para o campo educacional. 
No Art.5 do Plano, ainda pode ser observado no inciso II, que é dever das instâncias regulatórias analisar e propor políticas públicas para assegurar a implementação das estratégias e o cumprimento das metas. Ou seja, as políticas públicas para materialização desta Lei são desenvolvidas pelo MEC, CNE e o Fórum Nacional de Educação.

O PNE apresenta o quantitativo de vinte metas para a educação brasileira. Para alcançálas são estabelecidas estratégias, que apresentam as especificidades que se coadunam com o propósito da meta, bem como deixa mais evidente as ações que deverão ser realizadas para alcançar o objetivo maior.

As Metas 1, 2 e 3 tratam da Educação Infantil, do Ensino Fundamental e do Ensino Médio, respectivamente. A meta 4 aparece com o intuito de atender as especificidades da educação inclusiva. As metas 5, 7 e 8 voltam seu olhar para a alfabetização e a aprendizagem na idade certa. As metas 9 e 10 têm como objeto a formação dos jovens e adultos, bem como a articulação da modalidade EJA à Educação Profissional.

A meta 11 discorre a respeito especificamente da Educação Profissional. Tem-se como intuito triplicar as matrículas da Educação Profissional Técnica de nível médio, assegurando a qualidade da oferta e pelo menos $50 \%$ da expansão no segmento público (BRASIL, 2014). Apesar de existir uma meta especificamente para a Educação Profissional, não constatamos a presença, nas estratégias, de discussões voltadas para formação de professores para esse campo de oferta educacional $^{1}$.

As metas 12,13 e 14 traçam objetivos globais para a Educação Superior e carreira docente nesse nível de ensino. No que tange a formação e valorização de professores da educação básica, localizamos discussões a respeito das metas 15, 16, 17 e 18. As metas 19 e 20 centram seu olhar no financiamento e na gestão da educação.

Na Figura 1 essas metas podem ser melhor explicitadas

\begin{tabular}{|c|c|}
\hline \multicolumn{2}{|c}{ METAS DO PNE } \\
\hline META 1 & Educação Infantil \\
META 3 & Ensino Fundamental \\
META 4 & Ensino Médio \\
META 5 & Educação Especial \\
META 6 & Alfabetização \\
META 7 & Educação Integral \\
META 8 & META 9 \\
META 10 & Aprendizado adequado no tempo certo \\
META 11 & Escolaridade média \\
META 12 & Alfabetização e alfabetismo de jovens e adultos \\
META 13 & EJA integrada à Educação Profissional \\
META 14 15 & Educação Profissional \\
META 16 & Educação Superior \\
META 17 & Titulação de professores da Educação Superior \\
META 18 & Pós-graduação \\
\hline
\end{tabular}

\footnotetext{
1 Vale destacar que não foi localizada discussão sobre formação de professores para Educação Profissional especificamente nas estratégias da meta 11.
} 
META 19

META 20
Gestão democrática

Financiamento da Educação

Figura 1: discriminação das metas do PNE (2014-2024)

Fonte: autoria própria

A Lei no 13.005/2014 discorre a respeito do professor da Educação Básica em quatro metas: 15 (Formação de Professores), 16 (Formação Continuada e Pós-Graduação de Professores), 17 (Valorização do Professor), 18 (Plano de Carreira Docente). Observamos, portanto, um expressivo número de metas voltadas especificamente ao principal profissional responsável pelo processo de ensino e aprendizagem no ambiente escolar, o professor.

Se levado em consideração o quantitativo total de metas (20), observamos que $20 \%$ destas estão voltadas ao professor, sua formação e valorização.

A meta 15 discorre a respeito da formação docente, tendo como objetivo garantir, em regime de colaboração entre a União, os Estados, o Distrito Federal e os Municípios, no prazo de 1 ano de vigência deste PNE, política nacional de formação dos profissionais da educação de que tratam os incisos I, II e III do caput do art. 61 da Lei no 9.394, de 20 de dezembro de 1996, assegurado que todos os professores da educação básica possuam formação específica de nível superior, obtida em curso de licenciatura na área de conhecimento em que atuam.

No que concerne ao regime de colaboração, é estabelecido, a partir das estratégias que este apresente um caráter de diagnóstico das necessidades de formação de profissionais da Educação e da capacidade de atendimento por parte de instituições públicas e comunitárias de Educação Superior existentes nos Estados, Distrito Federal e Municípios e defina obrigações recíprocas entre os partícipes.

À União cabe a função de financiar essa formação e avaliá-la. Em suas estratégias, a Lei não evidencia se essa formação é prioritariamente pública. Ao contrário, abre espaço para a iniciativa privada nas estratégias 15.2 (financiamento estudantil) e 15.3 (iniciação à docência) receber dinheiro público para que o estudante financie a licenciatura em instituições privadas, bem como estas mesmas instituições recebam verba advinda do Programa Institucional de Bolsas de Iniciação à Docência (PIBID).

No que diz respeito à formação do professor que atua na Educação Profissional, a estratégia 15.3 diz que é preciso desenvolver modelos de formação docente para a educação profissional que valorizem a experiência prática, por meio da oferta, nas redes federal e estaduais de educação profissional, de cursos voltados à complementação e certificação didáticopedagógica de profissionais experientes.

Notamos uma ênfase na questão da experiência prática, do saber do "chão da fábrica" nessa estratégia. Muitos dos professores que atuam na educação profissional, são bacharéis ou tecnólogos que, portanto, não apresentam formação em licenciaturas ou numa formação que trate de questões pedagógicas. Sendo assim, possivelmente eles sintam uma maior necessidade de aprofundamentos nessa área, para que possa efetivar o processo de ensino e aprendizagem dos seus discentes. Sendo assim, a estratégia deveria estar centrada em evidenciar essa necessidade e propor medidas para a transformação desse quadro de falta de formação pedagógica por parte dos docentes que atuam na Educação Profissional. 
De modo geral, as estratégias da meta em questão evidenciam o regime de colaboração entre os entes federativos como mecanismo para se materializar a formação do professor, colocando os órgãos da União a serviço do mecanismo de avaliação das políticas públicas para essa finalidade. Além disso, percebemos que essas estratégias deixam brecha para que o investimento público seja inserido na iniciativa privada.

A meta 16 do PNE propõe formar, em nível de pós-graduação, $50 \%$ dos professores da Educação Básica e garantir a todos os (as) profissionais da Educação Básica formação continuada em sua área de atuação, considerando as necessidades, demandas e contextualizações dos sistemas de ensino. Essa meta é amparada em 6 estratégias que evidenciam, em suma, regime de colaboração entre os entes federativos ressaltando que essa formação deveria acontecer em instituições pública. Isso fica evidente já na estratégia 16.1, em que visa

\footnotetext{
realizar, em regime de colaboração, o planejamento estratégico para dimensionamento da demanda por formação continuada e fomentar a respectiva oferta por parte das instituições públicas de Educação superior, de forma orgânica e articulada às políticas de formação dos Estados, do Distrito Federal e dos Municípios (Brasil, 2014).
}

A meta 17 visa valorizar os (as) profissionais do magistério das redes públicas da Educação Básica, a fim de equiparar o rendimento médio dos (as) demais profissionais com escolaridade equivalente, até o final do 60 ano da vigência deste PNE.

Para isso, evidencia, em suas estratégias, um piso salarial nacional e um plano de carreira. A questão do plano de carreira chama a atenção por evidenciar que os professores sejam de qualquer rede pública de ensino, tenham um plano de cargo e carreira e que nele, seja decretada que o trabalho do professor deva acontecer em uma única instituição de ensino.

A esse último intento é estabelecido uma meta específica, a 18. Nela, observamos que sejam realizadas políticas públicas que assegurem, no prazo de 2 anos, a existência de planos de carreira para os (as) profissionais da Educação Básica e Superior pública de todos os sistemas de ensino e, para o plano de carreira dos (as) profissionais da Educação Básica pública, tomar como referência o piso salarial nacional profissional, definido em lei federal, nos termos do inciso VIII do art. 206 da Constituição Federal.

Dessa forma, como podemos perceber, o PNE intencionaliza as políticas públicas do próximo decênio para a educação brasileira e, sobretudo, para a formação e valorização do professor da Educação Básica. Sua função enquanto uma política de caráter regulatória apresenta especificidades muito bem delimitadas, com objetivos que se coadunam com as principais problemáticas da educação brasileira. Cabe a nós - sociedade civil - avaliarmos se as políticas serão implementadas e a quais interesses elas atenderão, se ao povo/trabalhadores ou os donos do capital.

\section{4 ÚLTIMAS CONSIDERAÇÕES}

No decorrer do texto, vimos que o Estado brasileiro é essencialmente capitalista, posto que reproduz a lógica do capital e está submetido aos interesses da classe dominante. Percebemos que as políticas públicas são ações do Estado - enquanto elemento de poder - para 
a sociedade civil e que atendem aos interessem dos burgueses. Essas políticas podem ser classificadas em três tipo, sendo que a regulatória apresenta especificidades, uma vez que ela regula todas as demais.

Estruturamos nosso estudo a partir disso, logo, iniciamos uma breve analise na Constituição Brasileira e na LDB, posto que essas leis regem todas as políticas públicas no Estado brasileiro. O objetivo foi de localizar as diretrizes para a formação dos professores. Depois disso, partimos para a analises do PNE, evidenciando os encaminhamentos para as políticas de formação de professores durante o decênio.

Vimos que as estratégias abrem espaço para investimento público na esfera privada, sobretudo no que tange à formação inicial de professores. Logo, percebemos que o PNE centra em atender as demandas dos interesses dos grandes empresários que são responsáveis pelas instituições de ensino privada.

Notamos que a formação de professores para atuar na Educação Profissional ainda é pautada no reducionismo prática do trabalho docente nesse campo de atuação. Algo bastante preocupante, uma vez que sabemos as especificidades e as fragilidades do professor que desenvolve sua atividade no ensino técnico e tecnológico.

Dessa forma, compreendemos que alcançamos o objetivo proposto, uma vez que discorremos a respeito do Estado capitalista, entendendo sua relação com as políticas públicas, para que assim, pudéssemos analisar as metas e estratégias do PNE (2014-2024). Por se tratar de uma lei com pouco tempo de vigência, nos limitamos a desenvolver uma abordagem mais descritiva sobre as metas e estratégias.

Fica como proposta para um trabalho futuro, uma análise sobre o cenário educacional da formação de professores no Brasil e a relação com as metas e estratégias do plano, buscando desenvolver uma análise sobre as políticas que se desencadearão por decorrência desta lei.

\section{REFERÊNCIAS}

AZEVEDO, S., Políticas públicas: discutindo modelos e alguns problemas de implementação. In: SANTOS JÚNIOR, Orlando A. Dos (et. al.). Políticas públicas e gestão local: programa interdisciplinar de capacitação de conselheiros municipais. Rio de Janeiro: FASE, 2003.

BRASIL. Constituição Federal de $1988 . \quad$ Disponível em: <http://www.planalto.gov.br/ccivil_03/Constituicao/Constituicao.htm>. Acesso em: 14 dez. 2015.

Lei de Diretrizes e Bases da Educação Nacional. Disponível em: https://www.planalto.gov.br/ccivil_03/Leis/L9394.htm>. Acesso em: 14 dez. 2015.

Plano Nacional de Educação (2014-2024). Disponível em: http://www.planalto.gov.br/CCIVIL_03/_Ato2011-2014/2014/Lei/L13005.htm>. Acesso em: 14 dez. 2015.

ENGELS, F., A Origem da família, da propriedade privada e do Estado. São Paulo: Bertrand Brasil, 1995.

FRIGOTTO, G., O enfoque da dialética materialista histórica na pesquisa educacional. In: FAZENDA, Ivani (Org.). Metodologia da Pesquisa Educacional. 6. ed. São Paulo: Cortez, 2000. p. $75-100$. 
SANTOS, B.S., $O$ estado, $o$ direito $e \quad a$ questão urbana. Disponível em: <http://www.boaventuradesousasantos.pt/media/pdfs/Estado_Direito_e_a_Questao_Urban a_RCCS9.PDF>. Acesso em: 11 mar. 2016.

OLIVEIRA, A.F., Políticas públicas educacionais: conceito e contextualização numa perspectiva didática. Disponível em: <http://www.sinprodf.org.br/wp-content/uploads/2012/01/texto-4políticas-públicas-educacionais.pdf>. Acesso em: 14 dez. 2015. 